\title{
Performance of Project Alliancing in Australasia: a Digest of Infrastructure Development from 2008 to 2013
}

\author{
Derek Henry Thomas Walker ${ }^{1}$, James Harley ${ }^{1}$ and Anthony Mills ${ }^{2}$ \\ ${ }^{1}$ School of Property, Construction and Project Management, RMIT University, Australia \\ ${ }^{2}$ School of Architecture and Built Environment, Deakin University, Australia
}

\begin{abstract}
Project and program alliances have been an accepted form of project procurement for public infrastructure engineering projects in Australia and New Zealand (Australasia). Alliancing often provides best value and superior value for money when compared to traditional approaches such as Design and Construct, however considerable debate continues about its success and applicability. This paper reports on three studies of completed construction project alliance performance in 2008, 2010 and 2012. Consolidated findings are presented on 61 project alliances, data is analysed and emerging trends discussed. Recent government policy changes in Australia at Federal and State level have led to a decline in the number of project alliances, however, while the volume of alliance activity is declining it still represents billions of dollars of infrastructure construction work being undertaken. Results also revealed that communication and trust between the executive leadership and operational management teams was a major factor contributing to the functioning of the alliance. Furthermore, the research identifies several key factors that were necessary preconditions for successful alliances.
\end{abstract}

Keywords: Project Alliances, Australian public infrastructure, project management.

Paper Type: Research article

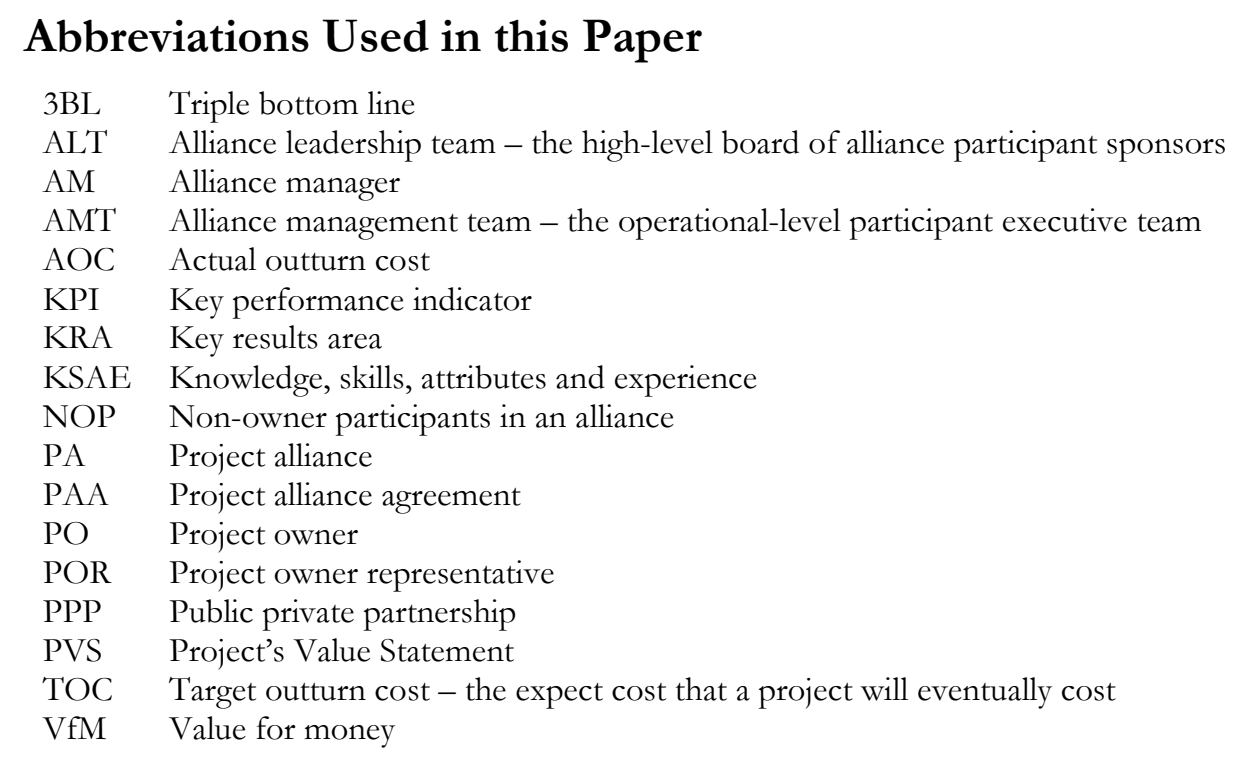

Copyright: Construction Economics and Building 2015. C 2015 Derek Henry Thomas Walker, James Harley and Anthony Mills. This is an Open Access article distributed under the terms of the Creative Commons Attribution 4.0 Unported (CC BY 4.0) License (https://creativecommons.org/licenses/by/4.0/), allowing third parties to copy and redistribute the material in any medium or format and to remix, transform, and build upon the material for any purpose, even commercially, provided the original work is properly cited and states its license.

Citation: Walker, D.H.T., Harley, J. and Mills, A., 2015. Performance of Project Alliancing: a Digest of Infrastructure Development from 2008 to 2013, Construction Economics and Building, 15(1), 1-18. DOI: http://dx.doi.org/10.5130/ajceb.v15i1.4186

Corresponding author: Derek Walker; Email - walker@rmit.edu.au

Publisher: University of Technology Sydney (UTS) ePress 


\section{Introduction}

Performance data from three surveys of construction alliance projects in Australia and New Zealand undertaken in 2008, 2010 and 2012, were analysed. Australian state, territory and federal governments have used Alliance Contracting from the late 1990s as a project delivery structure for complex public infrastructure projects. This approach has been significantly employed to overcome a range of negative impacts associated with traditional adversarial delivery approaches. Alliances embody a cooperative and collaborative mode of project delivery that relies on developing trust and aligning goals between project partners.

The Department of Finance and Treasury Victoria describes project alliancing as:

“... a method of procuring ... [where] All parties are required to work together in good faith, acting with integrity and making best-for-project decisions. Working as an integrated, collaborative team, they make unanimous decisions on all key project delivery issues. Alliance agreements are premised on joint management of risk for project delivery. All parties jointly manage that risk within the terms of an 'alliance agreement', and share the outcomes of the project" (2010, p.9).

Alliancing activity within the Australian construction project industry is significant. According to Wood and Duffield (2009, p.7) "The total value of alliance projects in the road, rail and water sectors in New South Wales, Victoria, Queensland and Western Australia, over the period 2004 to 2009 was $\$ 32$ billion". This level of alliancing has reduced, but is still highly significant with continued willingness to embrace this type of system in Australia.

Alliancing represents a project procurement approach in which the project owner's (PO's) representative (POR) maintains close interaction with the design and delivery teams throughout the project's execution. This can be contrasted with Public Private Partnerships (PPPs), the most popular infrastructure project delivery form (Regan, Love and Smith, 2013), in which the POR's involvement during the execution stage remains hands-off. Thus, alliancing remains a viable option for project owners who wish to retain close involvement in their projects across the design and delivery phases. It gives informed owners the ability to control project outcomes more precisely than with PPPs.

Alliancing offers clients a viable alternative to opportunistic action for highly complex and risky project delivery. A key advantage of the alliance approach is that it embeds collaboration, better facilitates innovation, and demands transparency and accountability (Clegg, et al., 2002; Davis and Love, 2011). The collaborative nature of the arrangement provides greater flexibility and effectiveness in coping with uncertainty than occurs with other procurement forms. This is because the partner organisations, being locked into the alliance with the Non-Owner Participants (NOPs), allows priorities to be agreed and innovations to be trialled very early in the project initiation and early design phase (Jefferies, Gameson and Chen, 2001; Hutchinson and Gallagher, 2003). It reduces participants' energy expended in defensive administrative routines to cover potential liability for risk and subsequent litigation (Lahdenperä, 2009; Laan, Voordijk and Dewulf, 2011). This positive outcome of the no-litigation agreement is supported by a requirement for consensus decisions making by the alliance management team (AMT) and the alliance leadership team (ALT), thus structurally undermining the grounds for litigation (Walker, Lloyd-Walker and Mills, 2014).

This procurement approach requires particular knowledge, skills, attributes and experience of participants and team members (Walker and Lloyd-Walker, 2011), however demand for rare talent produces a structural challenge to its widespread adoption. Time and energy demands placed upon senior executives in the ALT constrains the capacity of alliancing to become commonplace and makes it difficult to extensively propagate, globally or locally. Expansion of the alliancing concept is limited by the talent pool currently available or being developed. The 
authors were able to gain a broad picture of project alliance (PA) performance characteristics from analysing the combined study data of 61 alliance projects. Using this analysis, combined with knowledge from the authors' 15 years of previous studies into alliancing placed the researchers in a strong position to suggest trends and limitations of alliancing.

\section{Basic Theoretical Concepts}

Two key basic questions require explanation; what is a PA? Why should we use this approach?

\section{What is a PA?}

This paper is focused on project and program alliances rather than general/strategic business alliances described by Doz and Hamel (1998) or political alliances discussed by Machiavelli (Machiavelli and Bull, 1961). The Department of Finance and Treasury Victoria (2010, p.9) definition goes a long way towards characterising a PA. Ross (2003) emphasises the role of values that underpin a culture of collaboration facilitated by a set of contractual arrangements, and willingness of parties to work to the spirit of their alliance agreement. Authorities that explain how a project alliance is contractually configured (Morwood, Pitcher and Scott, 2008; Lahdenperä, 2010; Ross, 2010; Lahdenperä, 2012; Ross, 2013), stress the need for a three-limbed contract.

The commercial contract first limb spells out responsibilities and accountabilities of parties to the Project Alliance Agreement (PAA). These stipulate a reimbursable arrangement for all actual costs for delivering the project with open-book cost accounting, using appointed independent probity auditors with unlimited access to those accounts. The second limb of the contract is the overhead and profit fee for participants, identified and placed 'at-risk' in an agreed manner and subject to a painshare/gainshare arrangement. The target outturn cost (TOC) represents the final cost of the project developed by all PAA parties, including the project owner (PO). The third limb represents the "incentivation" aspects of the PAA with the painshare/gainshare agreement percentages for each participant. If PAA participants deliver the project at a cost that exceeds the TOC then they forfeit part of their overhead and profit to an agreed painsharing/gainshare formulae established in the PAA. If that cost is less than the TOC then savings are returned to the PAA participants in addition to their Limb 2 profit and overhead. The painshare/gainshare Limb 3 of the PAA contract incentive arrangements delivery incentives is based on key results areas (KRA) performance stipulated in the PAA.

The PAA not only describes what KRA 'performance' means but also specifies behavioural conditions that comprise the PA principles. These include a no-blame collaborative culture based on consensus decision making, so that parties cannot sue each other unless there has been demonstrable illegality or gross negligence. Alliance principles are explicit and contractual, in contrast to partnering type agreements where a partnering charter and partnering agreement tends not have 'teeth' (Morwood, Pitcher and Scott, 2008; Chan, Chan and Yeung, 2010).

This establishes a rigorous and accountable arrangement where trust that opportunistic behaviour is illuminated, through transparency and accountability and an open and collaborative culture. This contributes to an individual PA ambience that shapes how the PAA is implemented (Walker and Lloyd-Walker, 2014).

\section{Why should we use a Project Alliance approach?}

Motivations for choosing alliancing extend beyond the expected achievement of commercial drivers. KRAs range from standard 'iron triangle' (Time/Cost/Quality) performance criteria, as explained in the PMI PMBOK Guide ${ }^{\circledR}$ (PMI, 2013), to triple bottom line (3BL) measures. The 
3BL refers to performance expectations on environmental and social dimensions (Elkington, 1997; Australian Agency for International Development, 2003). Public infrastructure in particular aspires to both environmental, as well as social, value for money benefit.

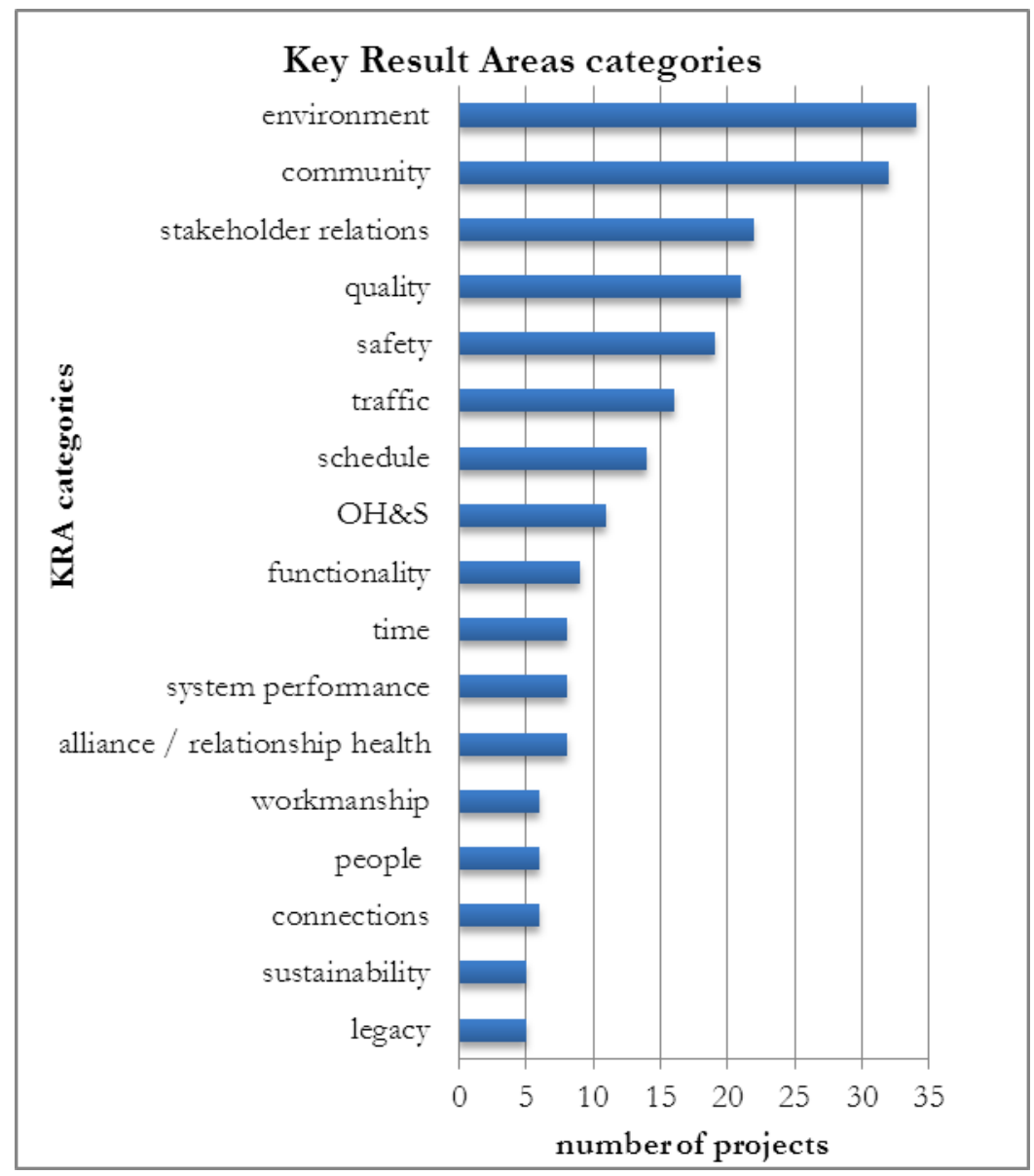

Figure 1: Frequency of KRAs

Figure 1 identifies the most commonly used KRAs charted across the total number of projects. The frequency of KRAs provides strong evidence that POs have a very keen interest in 3BL outcomes. This helps explain why alliancing is often associated with public infrastructure projects. In contrast, PPPs often have KRAs and key performance indicators (KPIs) that track similar desired outcomes KPIs embedded in their contractual agreement. Fine-tuning, recalibration and raising the bar for PPP KPIs as the project progresses is removed from the PO's influence once a PPP syndicate is approved and the design and construction phase begins (Akintoye, Beck and Hardcastle, 2003).

Motivations for alliancing have a sustainability focus; sustainability in human capital, organisational knowledge, risk and uncertainty management. Alliances explicitly use KRAs that represent the project owners (PO) interpretation of value with alliance team selection and performance measurement linked to KRAs (Hutchinson and Gallagher, 2003; Ross, 2003; 2013).

Alliances provide a particular project procurement approach where the owner seeks a strong hands-on involvement through its alliance agreement with a selected consortium of NOPs. This alliance of PO and NOPs jointly lead project delivery of the output (a road, train line, sewage treatment plant or museum that is delivered) as well as outcome (the lasting impact of the artefact delivery as well as value derived from the delivery process). An alliance also incorporates 
behavioural 'value' into the PAA. This includes unanimous decision making by alliance management and leadership teams, a no-blame culture resulting in no-litigation and an integrated one-team sink-or-swim together mind set (Hauck et al., 2004). Together these form the necessary social cohesion to build the social capital required for the alliance concept to be operationalised.

\section{Research Approach}

Three research studies into alliances were conducted in $2008(n=30), 2010(n=18)$ and 2012 $(n=13)$ using a telephone structured survey technique to gather data on each of the 61 cases. All projects had recently been completed in the previous year, and respondents were asked to provide actual data from the project, or reflect on their experiences. Some respondents were unable to disclose or find data on several questions asked of them as they had moved on from those completed projects and so did not have access to that data any longer. Each of the projects was unique, so that projects in 2008 for example were not included in the 2010 survey.

Participants for the survey were drawn largely from a database of Alliance Association of Australia membership and the Chief Executive Officer of that organisation provided introductions to the contacts. An email was sent to all potential participants outlining the research approach, and attaching a Plain Language Statement consent form and the list of questions. The research protocol followed all of our university research ethics requirements. The research survey instrument remained consistent over this period, for questions regarding TOC, time and KRAs. However, new questions were added in 2010 to uncover issues in value, collaboration, workplace culture and innovation. Participants were interviewed over the phone after having received a copy of the questionnaire and given some time to gather data requested. Many of the questions led to dialogue between researchers and participants so notes were also taken.

The survey instrument comprised 52 questions that were developed from an extensive review of the construction and project management literature as well as general management literature. Twelve questions related to fundamental performance, for example Q2 'What was the final approved TOC of the project?' followed by Q3 'What was the actual TOC (at the end of the project)?' Questions 13 to 20 related to aspects of commitment to 'best for project'. Value delivery questions comprised Q21 to Q28. Questions 29 to 35 addressed team collaboration communication and integration issues. Questions 36 to 45 focused on workplace culture. Questions about innovation (not reported upon here) on the project comprised Q46 to Q50. The final two questions related to early contractor involvement (ECI) as this aspect of constructor/designer/PO collaboration has been found to be highly effective in facilitating superior project delivery performance (Sidwell and Mehrtens, 1996; McGeorge and Palmer, 2002; Rahman and Alhassan, 2012). Participant survey interviews took 60 minutes on average.

Survey data were then analysed using Microsoft Excel to develop a representative general pattern of alliancing, rather than test for specific difference between alliances. While the dollar value of alliancing has been highly significant, the number of alliances undertaken across that period is unknown and data supplied to the Australian Bureau of Statistics does not provide breakdown of projects to identify alliances. However, the chief executive officer of the Alliance Association of Australia that represented most organisations involved in alliances in the engineering infrastructure sector during the survey period, felt that our sample size provided an adequate representation of alliancing activity.

Research limitations can be generally summarised as follows:

1. The sample size is indicative and most likely is representative but this is uncertain so it is safer to use the reported results as indicative and not conclusive; 
2. It is unwise to undertake more sophisticated statistical analysis to investigate withinsample and between-sample variance because it is questionable that this would add significant levels of confidence in the indicative findings;

3. The survey has 59 projects from Australia and only two projects from New Zealand. However, New Zealand and Australia use the same basis for their PAA in terms of PA conditions and KRAs (Crevani, Lindgren and Packendorff, 2010);

4. The survey provides data on projects completed during those years 2008, 2010 and 2012

5. Alliance managers were contacted because they would have had the most reliable overall perspective of the alliance and its performance. This is a restrictive source and it would have been preferable to have identified five or six key NOPs for each alliance, however we were limited by time, people availability and funding.

\section{Research Findings}

Findings suggest evidence of a significant industry improvement in large-scale engineering infrastructure project delivery. The construction industry has had a poor reputation in most countries: for project cost and time over runs; a litigious culture; poor stakeholder management; and scant regard for environmental issues through waste and pollution. Reports in the UK such as Latham (1994), Egan (1998; 2002) and others in Australia (NBCC, 1989; Ison and CIDA, 1994) provide a backdrop to concerns about the traditional construction and engineering industry image. It was in response to this grim reality that relationship based procurement forms evolved and were encouraged (Rowlinson and McDermott, 1999; Cheung et al., 2005; Anvuur, Kumaraswamy and Mahesh, 2011).

\section{Alliance Performance}

Most POs take a keen interest in the Actual Outturn Cost (AOC) of a project and how that compares to their expectations and authorisation of the initial TOC. The initial TOC may be influenced and amended through authorised scope changes (positive or negative) to arrive at a final authorised TOC. If the AOC is substantially less than the final TOC then critics may argue that the estimates and assumptions used to develop the TOC were too easy to achieve. This may be the case or it may well be a result of a combination of high levels of innovation, excellent management, excellent teamwork or just good luck. If the AOC is greater than the final approved TOC then the reverse may be true.

Survey results can be misleading or may disguise valuable information about trends so it is important to carefully consider how results are presented to focus on presenting clear, valid and understandable trends (Sekaran, 1992; Zikmund, 1994; Fellows and Liu, 1997). The authors decided to initially provide descriptive summary statistics for the actual TOC compared to the final TOC figure and to then illustrate the results graphically. Cost and time results were closely related so the logic of the results is illustrated by cost statistics. Other results presented are based on interval assessment. Likert scales of low to high can be presented in the form of descriptive statistics, mean standard deviations etc., but lack the impact of graphical displays. The statistics also lose meaning when the sample is small and for our data on team collaboration, workplace culture and innovation, the number of responses from the 2012 provided only 13 responses, so for the sake of clarity it was decided to illustrate these results graphically to show response numbers rather than a percentage figure.

In comparing the AOC to the final approved TOC with 61 results the following statistics were calculated. The mean percentage cost underrun between AOC and TOC was 4.07\% indicating that the mean figure for performance was $4.07 \%$ under budget. The minimum and maximum variance between AOC and TOC was 33.99\% underrun and 31.24\% overrun. The mean of the 
cluster that was under the TOC was $10.09 \%$ and the mean of the group over the TOC was $8.40 \%$. Figure 2 presented the difference between the actual and final TOC.

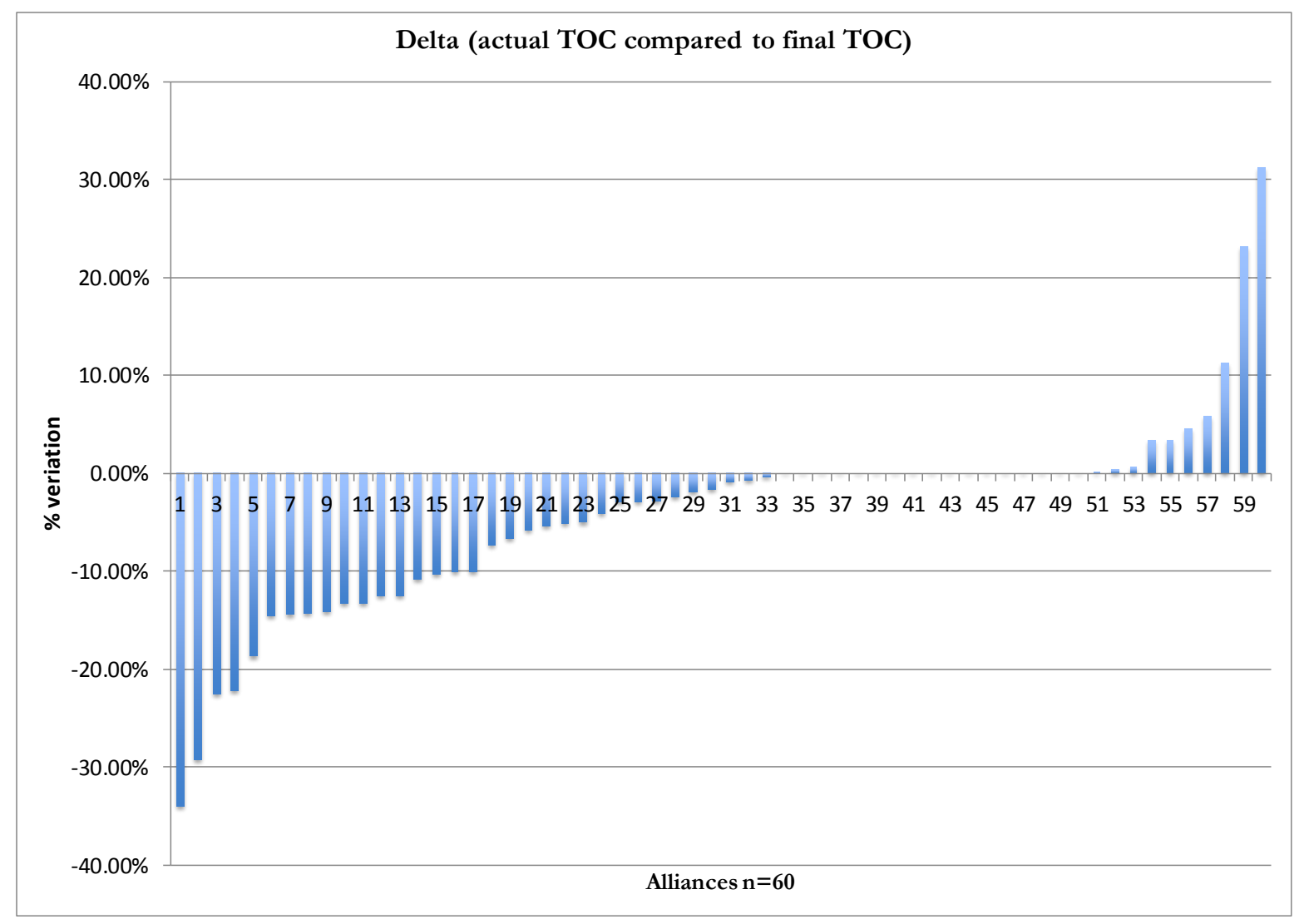

Figure 2: Delta (actual AOC compared to final TOC)

What can be concluded from this? First, only four of 60 projects were above $5 \%$ over with three being between $3 \%$ and $5 \%$ and three cases at less than $1 \%$ above zero. Scope creep may occur where the scope of capital expenditure and operations and maintenance items may be unclear, with the AOC not reflecting increased value delivered by the project through increasing capital costs, to reduce operational costs during the operational cycle of the asset's ownership. Many of the projects were delivered on-cost (17 of the 60) and 34 were delivered below cost. Most of these involved scope changes. Scope reduction reasons included decisions that were possible to be made due to the collaborative project delivery approach. Some budget items that may in a traditional procurement approach have been viewed as a 'contingency' risk item in a budget could be more fully investigated with the advantage of all PO and NOP knowledge, experience and insights once construction was underway, and uncertain or ambiguous situations could be clarified. Other reasons include innovation, process improvement and other positive outcomes stemming from use of the collaborative approach.

There was no evidence to suggest that these TOCs had over-generous budgets. Each project budget was produced in line with usual procedures and was not developed in any different way to other projects of the same type.

Respondents reported that on the five cases where the final TOC was markedly (greater than $15 \%$ ) below the actual approved TOC, scope change was the major reason. This could be interpreted as an inflated initial scope estimate, or the result of genuine better alliance team understanding of the situation, once all PA participants and the owner were able to collaborate 
and more accurately define the scope of work undertaken. Alliance teams usually revise project scope by agreeing that the functional outcomes of the project can be achieved by smarter designs achieved through the collaborative conversation.

These final project cost figures and their actual-to-final-TOC outcome presents an improved situation than that reported on many infrastructure projects in Europe (Flyvbjerg, Holm and Buhl, 2002; Flyvbjerg, Rothengatter and Bruzelius, 2003; Flyvbjerg, 2007) and concerns raised about the real cost of many PPPs (Grimsey and Lewis, 2005; Victorian Auditor General, 2007; Flyvbjerg, 2009; Williams, 2010). Participants stated that a PO hands-on involvement most effectively occurs where there is a knowledgeable and sophisticated POR to contribute insights as the asset owner. This provides more intelligent and effective assessment of risk, uncertainty and ambiguity.

General responses to questions asked about reasons for a variance between potential over or under AOC, compared to final approved TOC, which related to different processes or approaches facilitated by the alliancing approach. Scope changes were cited as the primary reason for PAs that were completed under the approved TOC, with innovation being cited as the second highest reason. Respondents cited similar reasons for time performance to that of cost performance.

Reason for AOC being UNDER final approved TOC - i.e. a cost under-run include:

- Savings achieved through risk management, accelerated processes and innovative practices

- Methodology improvements that were developed and which subsequently improved action on repetitive processes

- Risks not being realised

- Improved quality assurance

- Minimal business interruptions

- Significant reduction in scope

Reason for AOC being OVER final approved TOC - i.e. a cost over-run include

- Increased scope

- Delayed costs

- Delayed or extended approval processes, especially when heritage issues were involved

- Project delivered during a period of market volatility and economic boom which resulted in reduced availability and higher prices for resources

- The design being more complex than originally considered

- Under-estimation of design effort

- Additional elements included in the scope

- Delayed inclusion of a KRA

- Separate portion of the contract was negotiated after the commencement of the project and so was not factored into the initial TOC

Figure 3 indicates that of the 18 projects that were completed under the proposed time: four of these were more than $20 \%$ under schedule; eight of the remainder were greater than $10 \%$ under time; twenty eight projects came in on time; thirteen projects came in over the agreed schedule time; and seven of these were under 10\% over that time. Four projects were between $10 \%$ and $20 \%$ over scheduled time and three projects were over $20 \%$, two of those around $60 \%$ over time. 


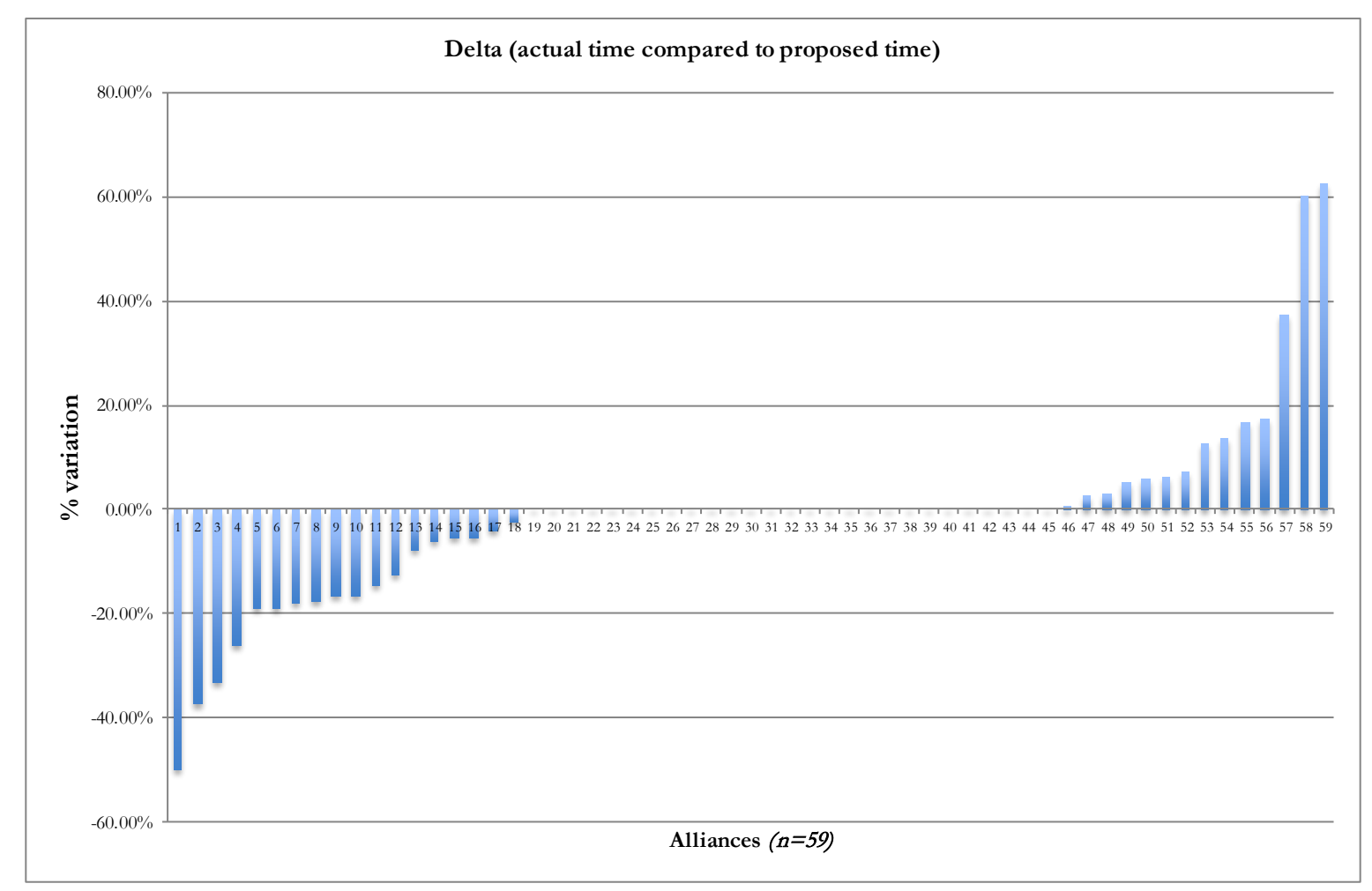

Figure 3: Delta (actual time compared to proposed time)

Cost and time results are important, but for alliances other KRAs were considered vitally important to project success. Respondents highlighted the formal arrangement between the client and partners as being a distinctive characteristic that defines alliancing, with a shared approach to problem solving and risk mitigation and one in which decisions are unanimously endorsed at the ALT and AMT level. The PO and NOPs act as a single team, to ensure they have aligned drivers and goals and share responsibility for achieving the KPIs that are measures for the PO identified KRAs that define the PO's perception of outcome value. Members of the ALT would generally be appointed responsible for a single KRA. This would ensure the KRAs remained visible at ALT level, whilst providing an executive link between the KRA and management. Similarly the AMT would normally be responsible for defining the KPIs associated with each KRA, thus closing the loop between operations, management and leadership considerations. The AMT develops a set of KPIs related to each KRA at the beginning of the project (although there have been instances where this process takes much longer) in an effort to lock down the indicators and associated metrics.

\section{Delivering Value}

KRAs and KPIs are means of defining, measuring and monitoring value. Specific questions were not asked in the 2008 survey about the form that a project value statement (PVS) may take but they were in the 2010 and 2012 surveys. Data on 31 projects illustrate how the expectation of value was expressed and communicated to NOPs and how value was perceived to have been delivered.

The PVS represents the summary of the Value for Money (VfM) proposition of the project that justified client investing in the project. Results imply that clients have been able to commence alliance engagement, through defining TOC and other constraints, without necessarily an articulation of what constitutes a value outcome. 
The data suggested that:

- Some respondents may not be sufficiently clear on how VfM for social and environmental 3BL aspects can be articulated in a readily-understood manner through the project/program business case;

- Continued use and primacy of the term VfM instead of 'best value' or project/program value, detracts attention from what is critical and important in value terms and this undermines perceived project or program success because it is limited by monetary definitions of value;

- It was inevitable that some respondents were brought into the alliance teams after others had left and they may have 'inherited' KRAs without these being fully explained and justified; and

- Perhaps all project business cases should include all three 3BL aspects in a VfM template, while accepting that for many projects the cost/commercial leg of the 3BL concept often dominates for political and budget-constraint reasons.

Question 22 asked respondents to identify at what point in time, during the bidding process, the PVS was communicated to the bidders or alliance teams. Respondents stated that in some cases the PVS was included as part of project proposal documentation. In some cases this appeared more like a value proposition that would provide the aims of a value statement. In other cases it was very clear that the VfM statement was included in the initial request for proposal documentation where the alliances needed to address VfM (as part of their submissions) to be approved prior to the agreement of the TOC.

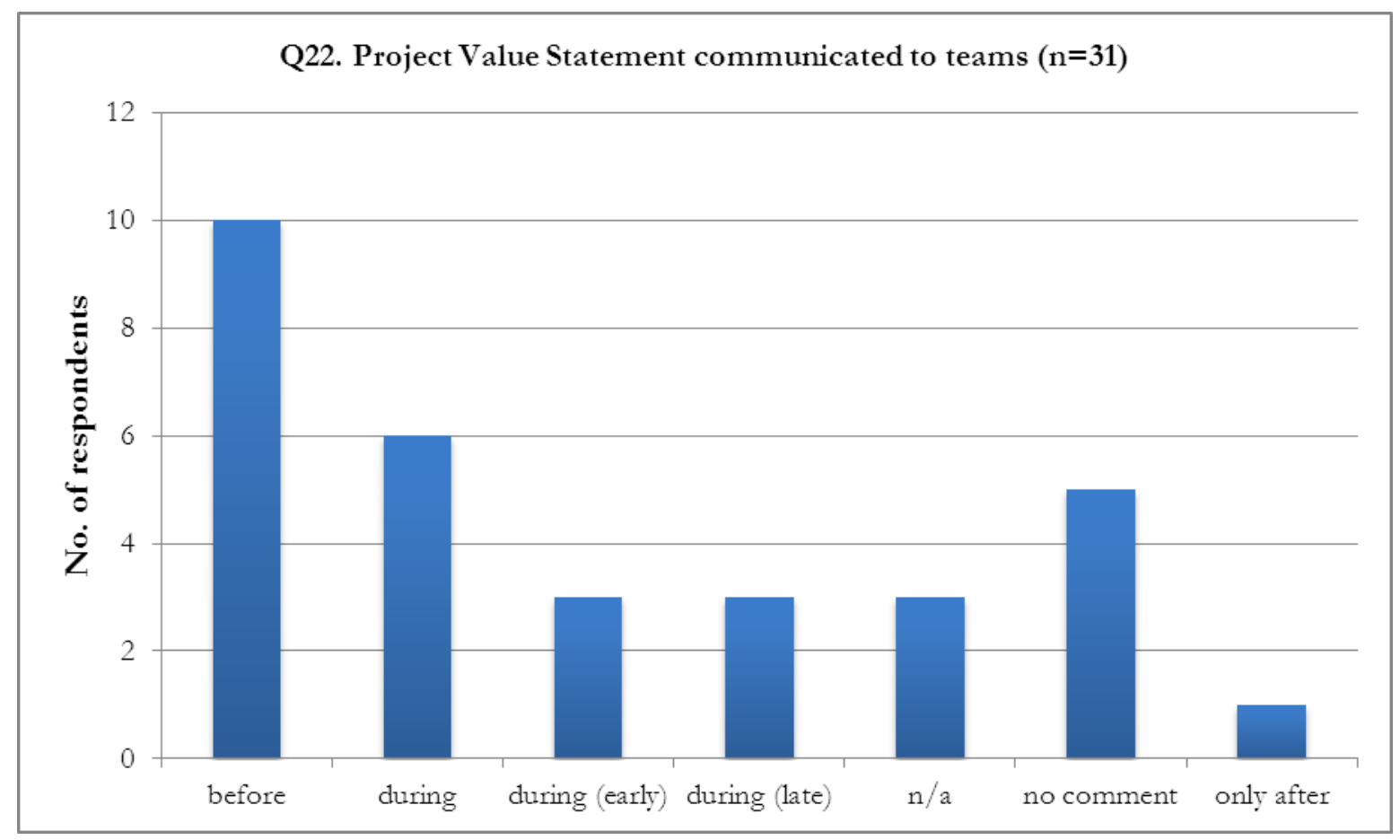

Figure 4: Project Value Statement (PVS) communicated to teams (2010 and 2012 Surveys)

Figure 4 indicates that $30 \%(\mathrm{n}=10)$ of respondents noted this communication occurred before the bidding process. For almost 40\% $(\mathrm{n}=12)$, it was undertaken during the bidding process. The PVS was included in the initial project documentation or included as part of the initial competitive 
alliance phase prior to the main alliance contract being awarded for those projects where communication of the PVS occurred before the bidding process began. In some instances it was included in the initial industry briefings.

The PVS may have been developed by the alliance team on formation of the alliance, or embedded in the definition of the KRAs which also were developed and confirmed post award of the contract for those projects where it was communicated during the bidding process. If the PVS was communicated early during the bidding process, this was because the terms of reference needed to be created in order to understand how value would be measured and the subsequent flow on effects to the alliances.

There were several reasons cited for the timing of the PVS being communicated later in the bidding process. In one instance the PVS came at the end of the TOC period and after the alliance was selected, and in another the alliance had to respond to a client's statement and demonstrate how it would meet the targets. In this instance, the respondent also noted some confusion (from the client's perspective) regarding the interpretation of value, noting that;

"The client had difficulty in really expressing the interpretation of the statement; it was rather ambiguous and very difficult to quantify. I remember reading a guideline from the Department of Treasury at the time which offered little clarification."

The above quote suggests that this may occur when a PO/POR is unclear about what precisely 'value' means then being compelled to explain this through collaborative workshops and meetings, helping NOPs crystallise the essence of value in the project and to effectively help shape the KRA and KPIs. The very act of having to explain something helps improve clarity as a dual conversation, with oneself as well as with others (Emerson, 1983; Vygotskii, 1986).

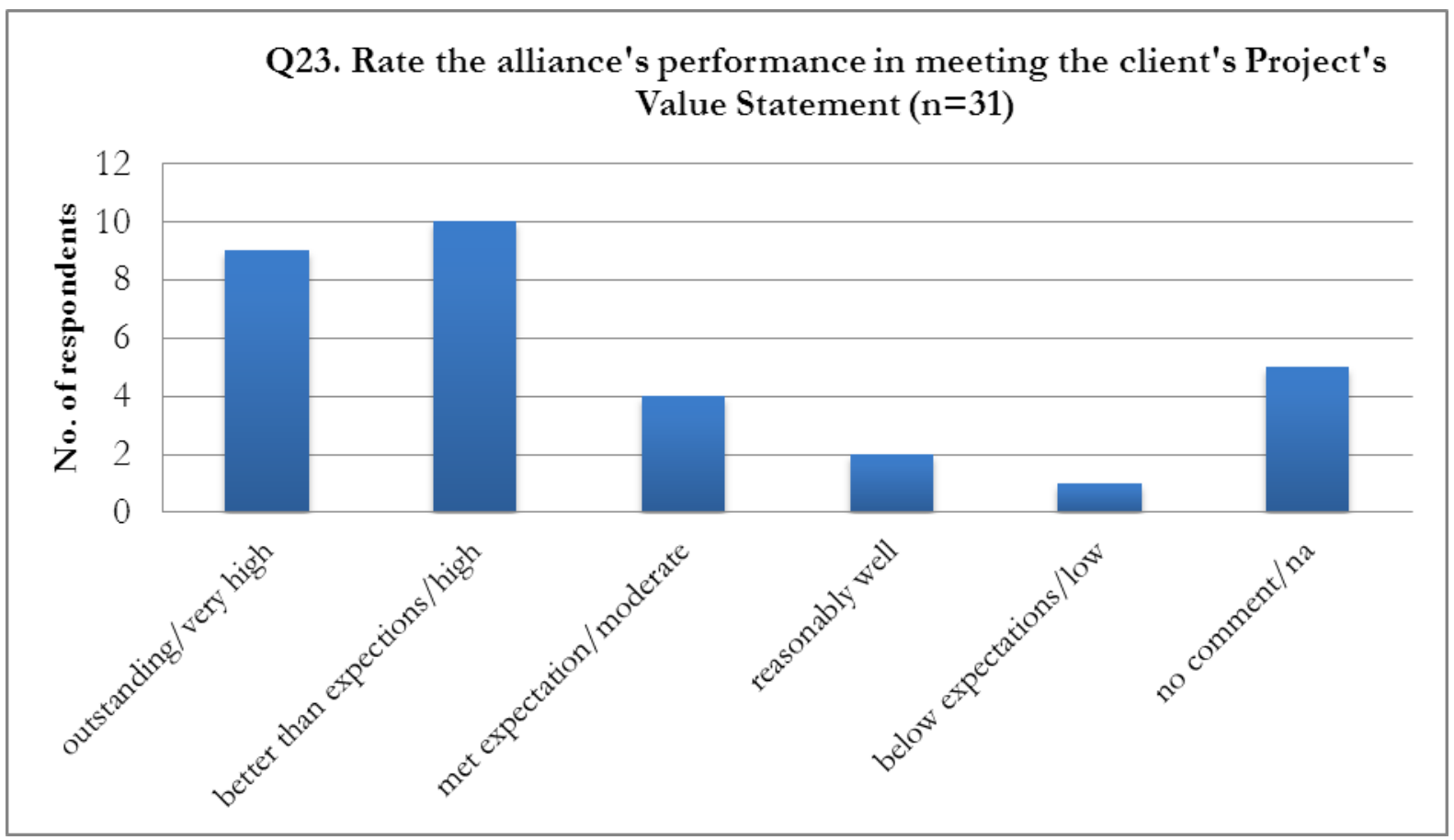

Figure 5: Rate the alliance's performance in meeting the PVS (2010 and 2012 Surveys)

Figure 5 illustrates the respondents' perception of the extent to which performance met the PO's expectations as expressed in the PVS. Approximately three quarters $(n=23)$ of respondents noted that the alliance, at a minimum, met the client's expectations of PVS. More than $60 \%$ of 
respondents $(\mathrm{n}=9)$ rated the outcome as outstanding/very high or better than expectations/high against meeting the PVS $(\mathrm{n}=10)$. Many respondents cited examples where the project had received industry recognition awards, and high client and ALT satisfaction.

"The performance of the Alliance can best be described by the awards achieved at state and national level from various industry bodies."

"Superb. Recognition by industry peers of the excellence of the project is evidenced by the winning of three awards"

Respondents overwhelmingly considered the alliance delivery approach to be superior in delivering value compared to design and construct or a design-bid-build delivery approach. Reasons most often cited included an eradication of contractual variations and possibility of claims turning into litigious circumstances, and the minimisation of disputes and stoppages. Respondents also noted that, due to the flexibility of project delivery approach, alliancing effectively allows projects that are of high risk or have complex unknown factors, to be managed efficiently whilst also engaging in innovative practices.

"The alliance delivery method better addressed the complexities and risks associated with the design and construction. Previous endeavours on similar infrastructure projects had resulted in litigation."

The alliance delivery approach was seen to accommodate community stakeholder requirements whilst maintaining awareness of scope and cost factors with a focus on 'best for project' and shared collaborative environment. It produces a mutually cooperative environment that addresses the requirements of the project rather than the letter of the contract.

\section{Collaboration}

Collaboration is central to explaining levels of perceived project success using the alliancing approach. Collaboration is supported within PAs by a unified best-for-project mind set and joint cross-disciplinary and cross-team workshops and small group discussion of issues, and the exploration of potential solutions, followed by unanimous decision making about the way to proceed with unified action. Three key questions were asked in the 2010 and 2012 surveys providing 13 responses about the mechanisms used for supporting collaboration and Figure 6 illustrates the responses.

Q30 - How effectively did the AM ensure relevant formal and/or informal communication to support AMT problem-solving and decision-making?

Q31 - How effective was the AMT in collaborative problem-solving and decision-making?

Q32 - How effectively did the AM act as a bridge to communicate relevant formal and/or informal information to and from the ALT for providing leadership and direction to the AMT?

We received 13 responses to key questions that gauged effectiveness of the AMT and ALT teams in achieving a unified and positive project outcome.

Q33 - How effectively was the AMT/ALT relationship in supporting collaborative problemsolving and decision-making?

Q34 - To what extent was the physical proximity of the AMT a contributor to supporting collaboration?

Q35 - To what extent were the virtual (ICT) tools of the AMT a contributor to supporting collaboration?

Figure 7 illustrates the response to Q33-35 that suggest the AMT and ALT were rated very highly as being able to support collaborative problem-solving and decision-making. 


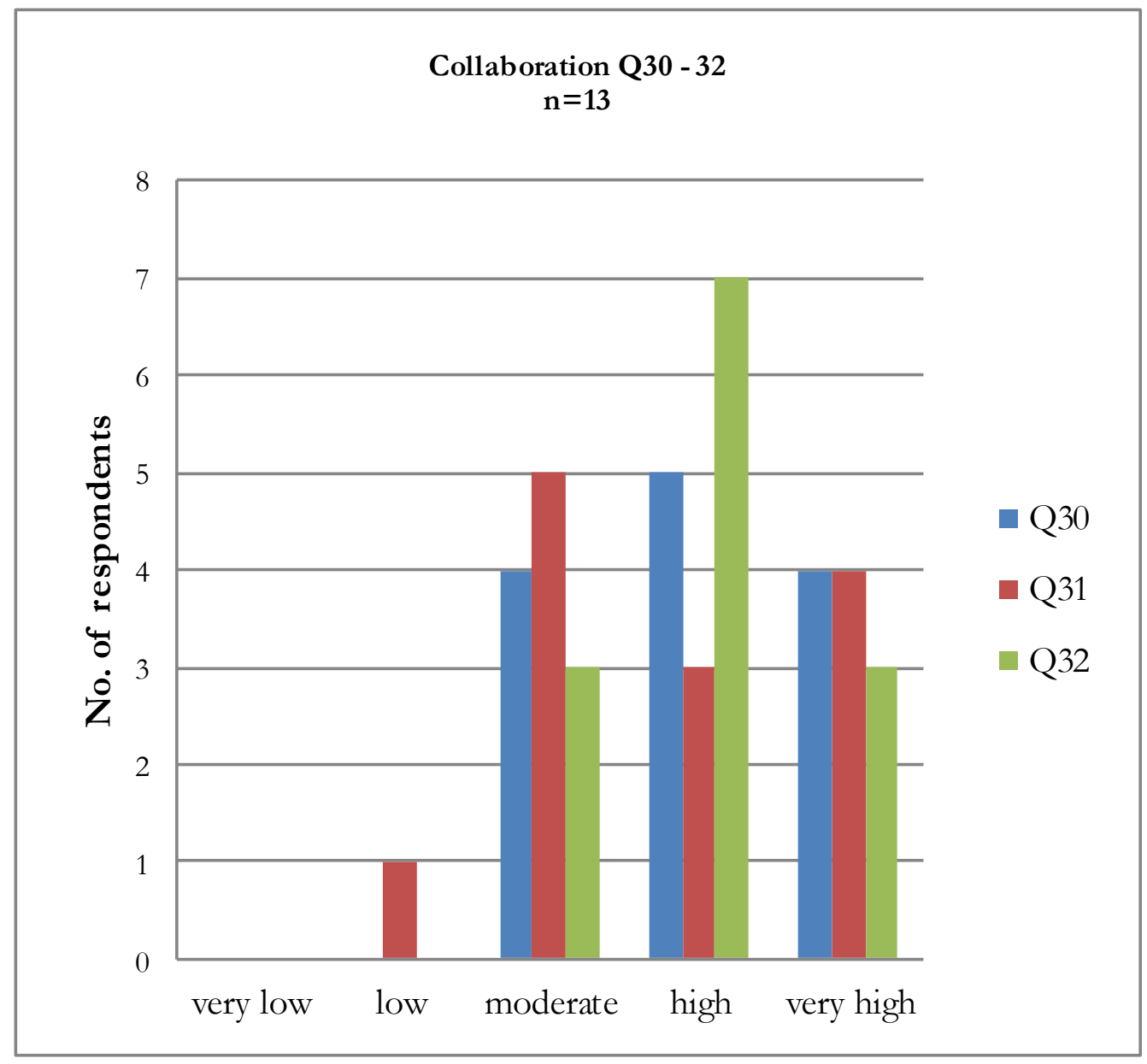

Figure 6: Collaboration Q30 - 32 (2012 Survey only)

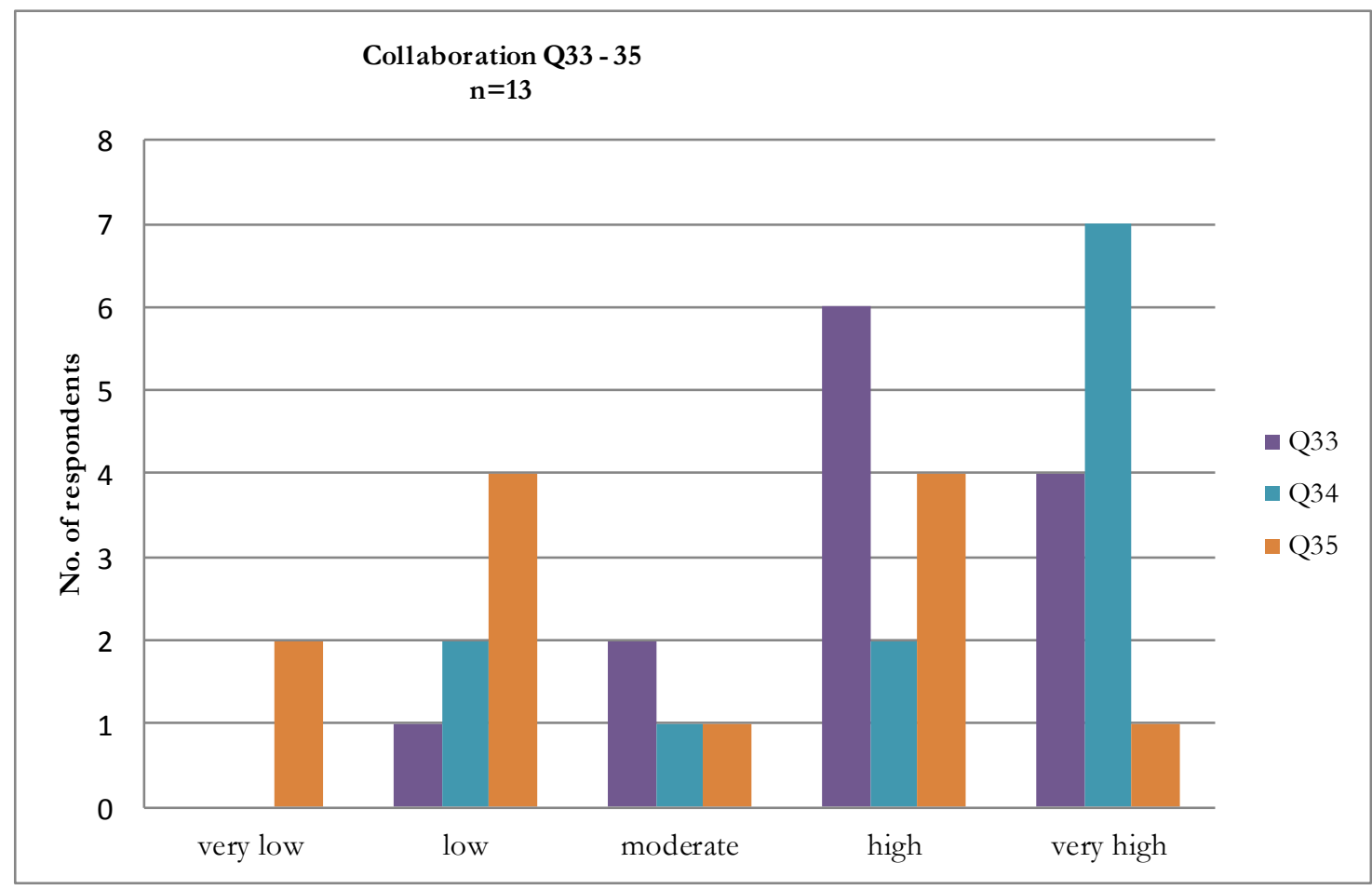

Figure 7: Collaboration Q33-35 (2012 Survey only) 
Respondents noted that AM competency and make-up of the AMT/ALT directly influences collaboration ability. Without a strong leadership and inclusive management style, barriers to knowledge sharing and transfer cannot be overcome and people resort to a silo approach. Colocation is important as it facilitates effective cross-team communication and dealing with issues as they emerged. This might take the form of ad hoc AMT/ALT forums, or informal workshops to deal with a pressing matter.

\section{Workplace Culture}

Questions were asked relating to the quality of collaboration in terms of the nature of the workplace culture. To effectively collaborate and share knowledge, team members need to feel safe and secure in voicing opinions, feelings and exchanging knowledge (Szulanski, 1996; von Krogh, 1998; von Krogh, Ichijo and Takeuchi, 2000). We received 13 responses from five key questions that gauge the effectiveness of the AMT and ALT teams in achieving a unified and positive project outcome.

Q36 - To what extent did the AMT perceive that 'we all sink-or-swim together'?

Q37 - To what extent did AMT members protect their own interests at the expense of other AMT members?

Q38 - To what extent did AMT members stick to their work and commitments?

Q39 - To what extent did the ALT pursue a coherent course in leading the project?

Q40 - To what extent did the AM pursue a coherent course in managing the AMT?

Figure 8 illustrates the degree of team cohesion as well as the quality of alignment of rhetoric and action relating to how team commitment and cohesion operated.

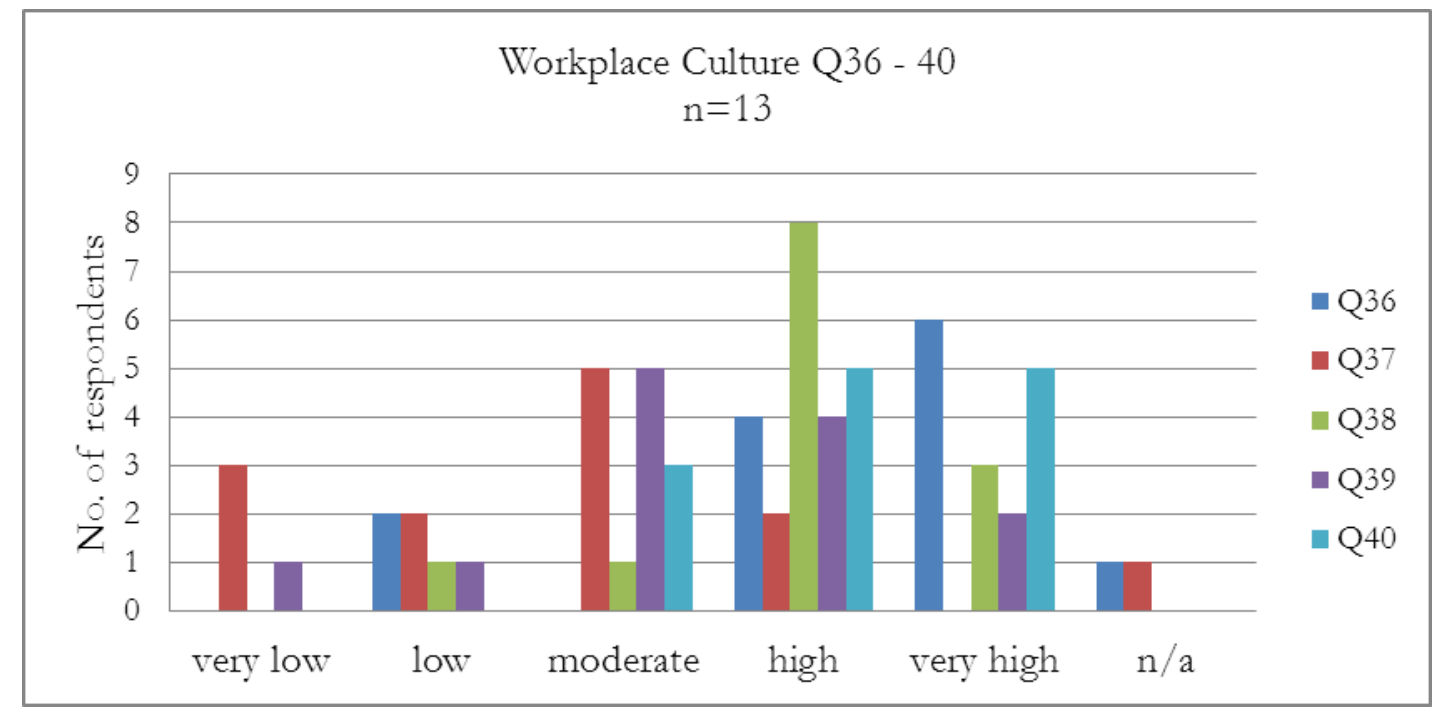

Figure 8: Workplace culture Q36-40 (2012 Survey only)

Past research in the area suggested that alliance decisions should be made on the basis of 'best for project' rather than 'best for individual' (Hauck et al., 2004). This shifts the project team from traditional adversarial contracting, where compensation is tied to the party's performance, to one that encourages collaboration and innovation. 
Respondents rated the AMT high to very high in the perception that it understood the concept that 'we all sink-or-swim together' on the project in achieving the KPIs together, rather than their performance being judged on individual team performance (Hauck et al., 2004). Some respondents believed that the AMT may have acted in their own interests at times, even though AMT members stuck to their work commitments.

\section{Trends in Alliances}

Reflecting on this study we can conclude that:

1. Changes in State and Commonwealth Government policy has influenced a change in emphasis on demonstrating best value to a cost 3BL priority

2. The trend in emphasising lowest cost has shifted from a single TOC concept based on a 'best team' selection process, towards a competitive dual TOC approach.

3. The alliance approach is successful in delivering broader 3BL outcomes on 'public good' projects and that continued adoption and adaptation of this approach effectively meets societal needs.

4. Other collaborative project procurement forms discussed and explored in the PMI study (Walker and Lloyd-Walker, 2015), such as ECI and integrated project delivery may emerge more strongly in Australia over time, for projects where the full alliance model is not deemed suitable, but where collaboration is essential.

5. Companies now seek to embed the value of collaboration aspiration into many nonalliance projects, for example a unique case study of an alliance being incorporated into a PPP project was recently reported (Jacobsson and Walker, 2013).

6. Alliancing offers a valuable upskilling experience for small and medium sized firms in regional and rural areas, as a result of working in program alliances.

7. Australia holds a unique place in the world as being the most experienced country in delivering infrastructure alliances. This suggests a commercial opportunity for major Australian contractors and design consultants to provide expertise to international alliances and to become global leaders in this project delivery approach. Some of the project owners who now have deep experience of alliancing are in a strong position to offer services to other international infrastructure project owners based on expertise they have gained through this period of intensive alliancing in Australia.

8. As more commercial organisations find it necessary to adopt corporate social responsibility measures, the 3BL KRA model may tip from its current dominance of a commercial outcome, towards the social and environmental poles, making alliancing more common in the private sector.

\section{Conclusions}

Project alliancing is suitable for the delivery of projects with particular characteristics; high-risk, tight timeframe, complex stakeholder issues and complex external environments, however, there is no guarantee that this will lead to optimum outcomes in practice (Chen et al., 2012). Ross (2003) suggests that alliances are being undertaken by clients without sufficient commitment to underlying principles. In some cases, this may result in projects where teams lack the attitudes and leadership skills needed to establish and sustain a high performing alliance. At best this may lead to sub-optimal alliances, at worst a breakdown in corporate relationships and serious project failures that would damage the reputation of the alliance model.

Alliancing represents a heightened level of project management where the project partners fully engage in project leadership and management teams to take on more demanding and complex projects. The objective of the project is to benefit the client through delivering high innovations 
levels for a functioning infrastructure. Intangible alliance behavioural outcomes include demonstrated mutual respect, collaborative process and action, and trust and commitment.

Project and program alliances represent a world class and advanced procurement choice that has demonstrated achieving exceptional project outcomes. Wood and Duffield (2009) criticised the approach, however Clifton and Duffield (2006) also argue that alliance principles could be of value if used within PPPs. This was demonstrated in a case study reported upon by Jacobsson and Walker (2013). One conclusion to be drawn is that alliances have a future not only in the project and program context, but also by being embedded in other procurement forms.

Clear conclusions can be drawn from this empirical work-alliances are applicable and successful within particular contextual conditions. They can be expensive to establish, include complex interfaces and are most suited to projects where there is a high level of uncertainty and ambiguity of scope, therefore the project procurement choice needs to be well understood by the PO/POR and NOPs.

The alliance team must be able to work within a culture of mutual respect, trust and commitment. It needs to have the flexibility to modify plans in order to achieve project goals, without recourse to finger-pointing and litigation. This requires a special skill set that is generally uncommon and difficult to source. A 'best for project' approach relies on the team appreciating that good long term outcomes will improve future relationships.

A firm conclusion can be reached that even if alliancing were to be massively increased (globally and within Australia) there would be a major shortage of requisite KSAE within the industry for all alliance parties. Continued involvement in alliancing needs to be maintained if we are to progressively grow the number of potential project participants with the necessary KSAEs.

\section{References}

Akintoye, A., Beck, M. and Hardcastle, C., 2003. Public-Private Partnerships: Managing Risks and Opportunities, Oxford: Blackwell Science Ltd. doi: http://dx.doi.org/10.1002/9780470690703

Anvuur, A.M., Kumaraswamy, M.M. and Mahesh, G., 2011. Building "relationally integrated value networks" (RIVANS). Engineering, Construction and Architectural Management, 18(1), pp.102-20. doi: http://dx.doi.org/10.1108/09699981111098711

Australian Agency for International Development, 2003. The Performance Management Toolkit: A Guide to Developing and Implementing Performance Management Plans, Report - 123. Canberra: AusAid.

Chan, Albert P.C \& Chan, Daniel W.M and Yeung, John F.Y., 2010. Relational contracting for construction excellence : principles, practices and case studies. New York: Spon Press, London

Chen, G., Zhang, G., Xie, Y.-M. and Jin, X.-H., 2012. Overview of alliancing research and practice in the construction industry. Architectural Engineering and Design Management, 8(2), pp.103-19. doi: http://dx.doi.org/10.1080/17452007.2012.659505

Cheung, F.Y.K., Rowlinson, S., Jefferies, M. and Lau, E., 2005. Relationship Contracting in Australia. Journal of Construction Procurement, 11(2), pp.123-35.

Clegg, S.R., Pitsis, T.S., Rura-Polley, T. and Marosszeky, M., 2002. Governmentality Matters: Designing an Alliance Culture of Inter-organizational Collaboration for Managing Projects. Organization Studies (Walter de Gruyter GmbH \& Co. KG.), 23(3), pp.317-37.

Clifton, C. and Duffield, C.F., 2006. Improved PFI/PPP service outcomes through the integration of Alliance principles. International Journal of Project Management, 24(7), pp.573-86. doi: http://dx.doi.org/10.1016/i.iiproman.2006.07.005

Crevani, L., Lindgren, M. and Packendorff, J., 2010. Leadership, not leaders: On the study of leadership as practices and interactions. Scandinavian Journal of Management, 26(1) pp.77-86. doi: http://dx.doi.org/10.1016/i.scaman.2009.12.003

Davis, P.R. and Love, P.E.D., 2011. Alliance contracting: adding value through relationship development. Engineering Construction \& Architectural Management, 18(5) pp.444-61. doi: http://dx.doi.org/10.1108/09699981111165167

Department of Finance and Treasury Victoria, 2010. The Practitioners' Guide to Alliance Contracting - 161, Melbourne, Victoria: Department of Treasury and Finance.

Doz, Y.L. and Hamel, G., 1998 Alliance Advantage - The Art of Creating Value Through Partnering, Boston: Harvard Business School Press. 
Egan, J., 1998. Rethinking construction - The report of construction task force, Report, London: Department of Environment, Transport and the Regions., ISBN 1851120947, pp.38.

Egan, J., 2002. Accelerating change. Rethinking construction, Report. London: Strategic Forum for Construction, ISBN 1 89867128 1, pp.44.

Elkington, J., 1997. Cannibals with Forks, London: Capstone Publishing.

Emerson, C., 1983. The Outer Word and Inner Speech: Bakhtin, Vygotsky, and the Internalization of Language. Critical Inquiry, 10(2), pp.245-64. doi: http://dx.doi.org/10.1086/448245

Fellows, R. and Liu, A., 1997. Research Methods For Construction, Oxford: Blackwell Science.

Flyvbjerg, B., 2007. Curbing Optimism Bias and Strategic Misrepresentation in Planning: Reference Class Forecasting in Practice. European Planning Studies, 16(1), pp.3-21. doi: http://dx.doi.org/10.1080/09654310701747936

Flyvbjerg, B., 2009. Survival of the unfittest: why the worst infrastructure gets built and what we can do about it. Oxford Review of Economic Policy, 25(3) pp.344-67. doi: http://dx.doi.org/10.1093/oxrep/grp024

Flyvbjerg, B., Holm, M.S. and Buhl, S., 2002. Underestimating Costs in Public Works Projects: Error or Lie? Journal of the American Planning Association, 68(3), p.279. doi: http://dx.doi.org/10.1080/01944360208976273

Flyvbjerg, B., Rothengatter, W. and Bruzelius, N., 2003. Megaprojects and risk : an anatomy of ambition. New York: Cambridge University Press. doi: http://dx.doi.org/10.1017/CBO9781107050891

Grimsey, D. and Lewis, M.K., 2005. Are Public Private Partnerships value for money?: Evaluating alternative approaches and comparing academic and practitioner views. Accounting Forum, 29(4), pp.345-78. doi: http://dx.doi.org/10.1016/j.accfor.2005.01.001

Hauck, A.J., Walker, D.H.T., Hampson, K.D. and Peters, R.J., 2004. Project Alliancing at National Museum of Australia - Collaborative Process. Journal of Construction Engineering \& Management, 130(1), pp.143-53. doi: http://dx.doi.org/10.1061/(ASCE)0733-9364(2004)130:1(143)

Hutchinson, A. and Gallagher, J., 2003. Project Alliances: An Overview, Melbourne: Alchimie Pty Ltd, Phillips Fox Lawyers, p.33.

Ison, Felicity and Construction Industry Development Agency (Australia), 1994. Two steps forward, one step back : management practices in the Australian construction industry. Sydney: Construction Industry Development Agency.

Jacobsson, Mattias and Walker, Derek H.T., 2013. Alliancing within a Public-Private Partnership. In: Steinthorsson R.S. , The $22^{\text {nd }}$ Nordic Academy of Management (NFF) Conference. Reykjavik, Iceland, 21-23 August 2013. Reykjavík, Iceland: University of Iceland Reykjavík.

Jefferies, M., Gameson, R. and Chen, S.E., 2001. The Justification and Implementation of Project Alliances Reflections from the Wandoo B Development. Journal of Construction Procurement, 7(2), pp.31-41.

Laan, A., Voordijk, H. and Dewulf, G., 2011. Reducing opportunistic behaviour through a project alliance. International Journal of Managing Projects in Business, 4(4), pp.660-79. doi: http://dx.doi.org/10.1108/17538371111164065

Lahdenperä, P., 2009. Project Alliance - The competitive single target-cost approach, Espoo: VTT Tiedotteita.

Lahdenperä, P., 2010. Conceptualizing a two-stage target-cost arrangement for competitive cooperation. Construction Management and Economics, 28(7), pp.783-96. doi: http://dx.doi.org/10.1080/01446193.2010.487534

Lahdenperä, P., 2012. Making sense of the multi-party contractual arrangements of project partnering, project alliancing and integrated project delivery. Construction Management and Economics, 30(1), pp.57-79. doi: http://dx.doi.org/10.1080/01446193.2011.648947

Latham, M., 1994. Constructing the Team, Final Report of the Government/Industry Review of Procurement and Contractual Arrangements in the UK Construction Industry. London: HMSO.

Machiavelli, N. and Bull, G., 1961. The Prince. Harmondsworth, Mddx: Penguin Books.

McGeorge, W.D. and Palmer, A., 2002. Construction Management New Directions. 2nd ed. London: Blackwell Science.

Morwood, R., Pitcher, I. and Scott, D., 2008. Alliancing, a participant's guide - real life experiences for constructors, designers, facilitators and clients. Brisbane: AECOM.

National Building and Construction Council, 1989. Strategies for the Reduction of Claims and Disputes in the Construction Industry - No Dispute. Canberra: National Building and Construction Council.

Project Management Institute, 2013. A Guide to the Project Management Body of Knowledge. Sylva, NC, USA: Project Management Institute.

Rahman, M. and Alhassan, A., 2012. A contractor's perception on early contractor involvement. Built Environment Project and Asset Management, 2(2), pp.217-33. doi: http://dx.doi.org/10.1108/20441241211280855

Regan, M., Love, P. and Smith, J., 2013. Public-Private Partnerships: Capital Market Conditions and Alternative Finance Mechanisms for Australian Infrastructure Projects. Journal of Infrastructure Systems, 19(3), pp.335-42. doi: http://dx.doi.org/10.1061/(ASCE)IS.1943-555X.0000136

Ross, J., 2003. Introduction to Project Alliancing. Alliance Contracting Conference. Sydney, Australia 30 April 2003. Sydney: Project Control International Pty Ltd.

Ross, J., 2010. Draft Project Execution Agreement. [online] Available at: http://www.pciaus.com/Downloads/PCI_PEA-model_B_01Nov2010.pdf [Accessed 1 November 2010]. 
Ross, J., 2013. Gainshare/painshare Regime - Guidance paper with sample model/drafting. [online] Available at: http://www.pci-aus.com/Downloads/PCI_Gainshare-GuideModel_A_07Feb2011.pdf [Accessed 07 February 2011].

Rowlinson, S. and McDermott, P., 1999. Procurement Systems: A Guide to Best Practice in Construction. London: E\&FN Spon.

Sekaran, U., 1992. Research Methods For Business - A Skill-Building Approach. New York: John Wiley \& Sons, Inc.

Sidwell, A.C. and Mehrtens, V.M., 1996. Case Studies in Constructability Implementation. Adelaide: Construction Industry Institute Australia.

Szulanski, G., 1996. Exploring internal stickiness: Impediments to the transfer of best practice within the firm. Strategic Management Journal, 17(Winter special Issue), pp.27-43.

Victorian Auditor General, 2007. Audit of 2 Major Partnerships Victoria Projects, Government Report PP no 60, Session 2006-2007 p.73. Melbourne: Victoria Auditor General's Office.

von Krogh, G., 1998. Care in Knowledge Creation. California Management Review, 40(3), pp.40-54. doi: http://dx.doi.org/10.2307/41165947

von Krogh, G., Ichijo, K. and Takeuchi, H., 2000. Enabling Knowledge Creation. Oxford: Oxford University Press. doi: http://dx.doi.org/10.1093/acprof:oso/9780195126167.001.0001

Vygotskii, A.L., 1986. Thought and Language. Cambridge, MA: MIT Press.

Walker, D.H.T. and Lloyd-Walker, B.M., 2011. Profiling Professional Excellence in Alliance Management Volume One Findings and Results. Sydney: Alliancing Association of Australasia.

Walker, D.H.T. and Lloyd-Walker, B.M., 2014. The ambience of a project alliance in Australia. Engineering Project Organization Journal, 4(1), pp.2-16. doi: http://dx.doi.org/10.1080/21573727.2013.836102

Walker, D.H.T. and Lloyd-Walker, B.M., 2015. Collaborative Project Procurement Arrangements. USA: Project Management Institute.

Walker, D.H.T., Lloyd-Walker, B.M. and Mills, A., 2014. Facilitating a No-Blame Culture through Project Alliancing. Project Perspectives, 8, pp.58-63.

Williams, T., 2010. Analysis of the London Underground PPP Failure. In: Taylor J.E. and Chinowsky, P., Engineering Project Organizations Conference. South Lake Tahoe, CA: Engineering Project Organization Society (EPOS).

Wood, P. and Duffield, C., 2009. In Pursuit of Additional V alue. A benchmarking study into alliancing in the Australian Public Sector - 191. Melbourne, Victoria: Department of Treasury and Finance.

Zikmund, W.G., 1994. Business Research Methods. London: Dryden Press, Harcourt Brace College Publishers. 